\title{
A PARTICULAR INFANTILE SCIMITAR SYNDROME VARIANT WITH ANOMALOUS SYSTEMIC ARTERIAL SUPPLY-INFERIOR VENA CAVA FISTULA
}

\author{
Carmen Suteu ${ }^{1}$, Cristina Blesneac ${ }^{2},{\text { Marian } \text { Pop }^{3}, \text { Amalia Fagarasan }^{3} \text {, and Rodica Toganel }}^{4}$ \\ ${ }^{1}$ Emergency Institute for Cardiovascular Diseases and Transplantation, Targu Mureș \\ ${ }^{2}$ Emergency Institute for Cardiovascular Diseases and Transplantation Targu Mures \\ ${ }^{3}$ University of Medicine, Pharmacy, Science and Technology of Tîrgu Mureș \\ ${ }^{4}$ University of Medicine and Pharmacy
}

October 8, 2020

\begin{abstract}
Scimitar syndrome is a rare anomaly, most commonly including partial pulmonary venous drainage into the inferior vena cava, hypoplasia of the right lung, and systemic collaterals from the aorta. We report a pediatric case in whom this rare syndrome was associated with intracardiac lesions and a large aberrant systemic arterial supply to the right lung that originated from the abdominal aorta and fistulated in the inferior vena cava.
\end{abstract}

\section{Hosted file}

Main document.pdf available at https://authorea.com/users/365518/articles/485582-aparticular-infantile-scimitar-syndrome-variant-with-anomalous-systemic-arterial-supplyinferior-vena-cava-fistula 

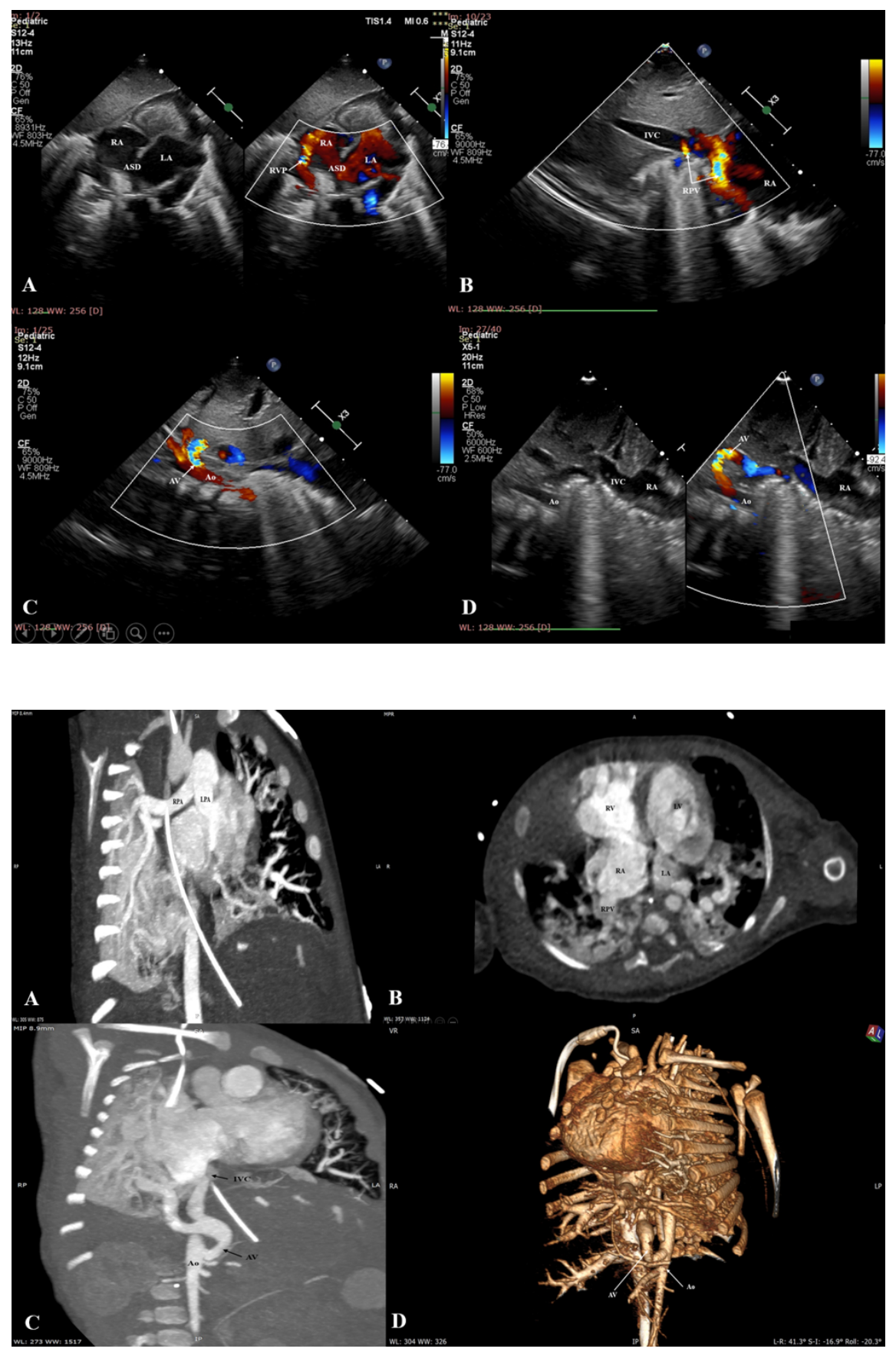


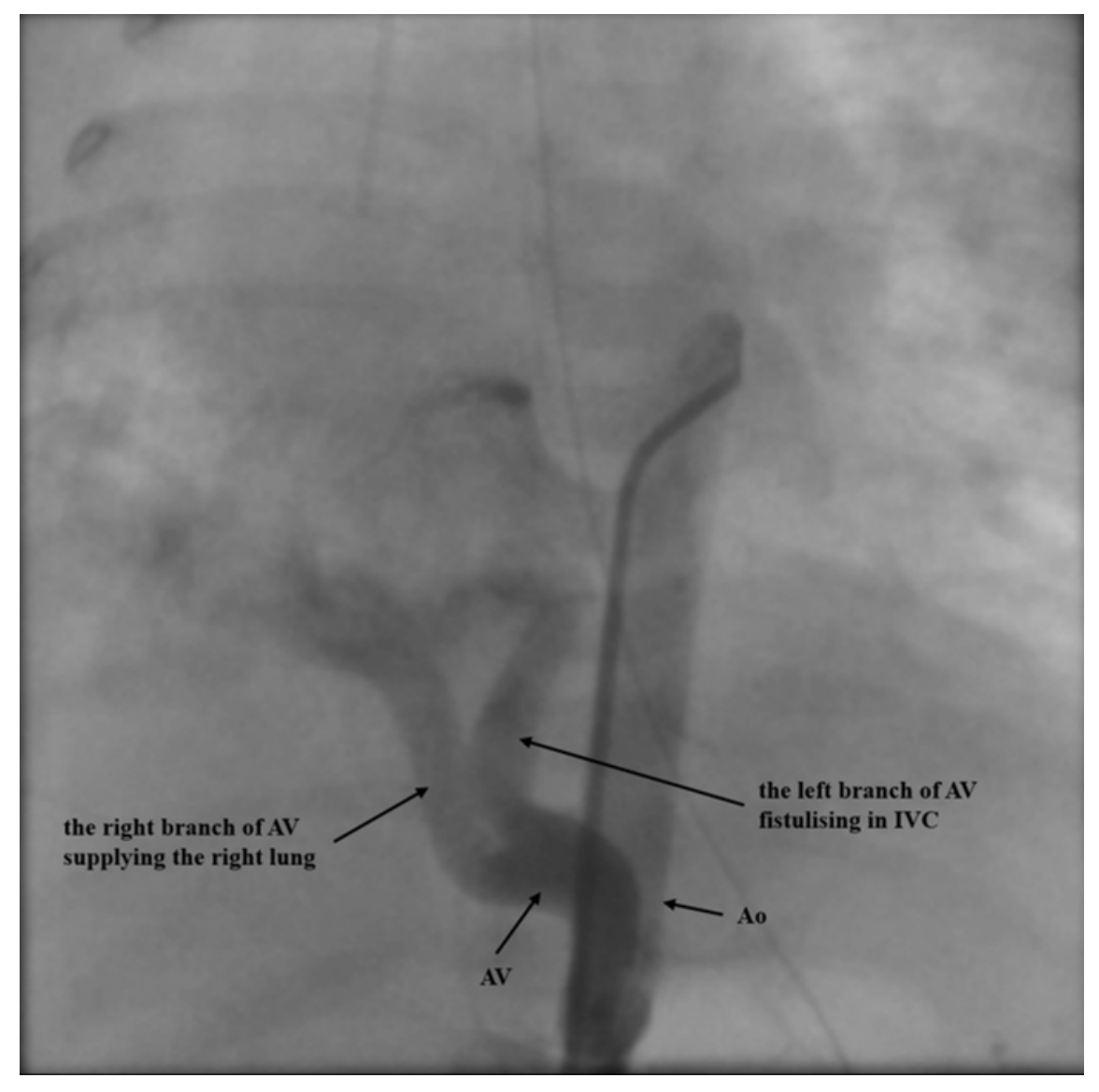

